\title{
VACCINATION IN INDIA
}

M way technologies. This is very much true in the field of medicine, nay in all the sciences. What is science? Is an excellent question and the best answer is "science is what scientists $d o^{\prime \prime}$. put differently in Dutch it sounds better Wetenschap Is Wat Wetenschappers Doen. Let us look at some of these . Lewis Thomas, former President of the Sloan-Kettering Cancer Centre in New York, in his book The Lives of a Cell classifies modern-technology in medicine into three groups".

(1) Non-Technology :- The so-called supportive therapy.

(2) Half-way Technology :-Technology designed to palliate (to cloak) symptoms and postpone death if possible! Outstanding examples being spare-part surgery, artificial organs, coronary bypass surgeries, angioplasties, cancer therapy etc. They are in addition, prohibitively expensive from the community point of view. Even today approximately $80 \%$ of the world population depends wholly or partially on traditional medicines for primary helth care.

(3) Really hi-tech: That which comes with good understanding of the disease process. This ciass is "highly sophisticated and profoundly primitive". It attracts least public notice. Lewis Thomas puts smallpox eradication by vaccination in this ategory.

Credit here must surely go to Edward Jenner but the real hero was that thirteen year old innocent boy, James Phipps, who did not know that he was being used as a guinea pig in a possibly fatal experiment, when Edward Jenner gave him an inoculation of live small pox virus. This was based on anecdotal information from a milk maid I. Norma, that people who

B.M.Hegde

Dean, Kasturba Medical College Mangalore 575001

India get cowpox (in latin vacca means cow) do not suffer from small pox. Edward Jenner did something which today's science and medical ethics would not have forgiven. Since the experiment succeeded, we applaud Jenner. If the experiment had failed the world would not have known that an innocent boy was killed by research misadventure ! God only knows how many innocent lives have been lost in such heroic experiments where the former were used unbeknownst to them. Few in the West know that we in India had an elaborate system of small pox vaccination, the details of which were documented 
by Dr. J. H. Holwell , F.R.S. in his letter to the President of the Royal College of Physicians of London in the year 1747 AD.

"On pursuing lately some tracts upon the subject of Inoculation, I determined to put together a few notes relative to the manner of Inoculation, practised, time out of mind by the Brahmins of Indostan; to this I was chiefly investigated, by the great benefit that may arise to mankind from a knowledge of this foreign method, which so remarkably tends to support the practice now generally followed with such marvelous success'.

The story of smallpox goes thus: "By the earliest account we have of small pox, we find it first appeared in Egypt in the time of Omar, successor to Mahomet; though no doubt, since the Greeks knew nothing of it, the Arabians brought it from own country; but might derive it originally from some of the more distant regions of the East".

The sagacity of the above conclusions, later times and discoveries has fully verified, three thousand years before $1747 \mathrm{AD}$ (five thousand years ago) as the indian scriptures institute a form of divine worship (Poojah) to the "Goddess of spots".

Inoculation is performed in Indostan by a particular tribe of Brahmins, who are delegated annually for this service from the different Colleges of Bindoobund, Eleabas, Banaras, \&c. Over all the distant provinces ; dividing themselves into small parties, of three or four each, they plan their traveling circuits in such ways as to arrive at the places of their respective destination some weeks before the usual return of the disease; they arrive commonly in the Bengal provinces early in February, although they some years do not begin to inoculate before March, deferring it until they consider the state of the season, and acquire information of the state of the distemper.

The inhabitants of Bengal, knowing the usual time when the inoculating Brahmins annually return, observe strictly the regimen enjoined whether they determine to be inoculated or not; this preparation consists only in abstaining for a month from fish, milk, and ghee, (a kind of butter made generally of buffalo's milk) ; the prohibition of fish respects only the native Portuguese and Mohammedans, who abound in every province of the empire.

When the Brahmins begin to inoculate, they pass from house to house and operate at the door, refusing to inoculate any who have not, on a strict scrutiny, duly observed the preparatory course enjoined them. It is no uncommon thing for them to ask the parents how many pocks they chuse their question on a matted seemingly so uncertain in the issue; but true it is that they hardly ever exceed, or are deficient, in the number required.

Previous to the operation the Operator takes a piece of cloth in this hand, (which becomes his perquisite if the family is opulent,) and with it gives a dry friction upon the part intended for inoculation, for the space of eight or ten minutes, then with a small instrument he wounds, by many slight touches, about the compass of a silver groat, just making the smallest appearance of blood, then opening a linen double rag (which he always keeps in a cloth round his waist) takes from thence a small pledgit of cotton charged with the variolous matter, which he moistens with two or three drops of the Ganges water, and applies it to the wound, fixing it on with a slight bandage, and ordering it to remain on for six hours without being moved, then the bandage, to be taken off, and the pledget to remain until it falls off itself; some times (but rarely) he squeezes a drop from the pledget, upon the part, before he applies it; from.the time he begins the dry friction, to tying the knot of the bandage, he never ceases reciting some portions of the worship appointed, by the Aughtorrah Bhade, to be paid to the female divinity before-mentioned, nor quits the most solemn countenance all the while. The cotton which he preserves in a double callico rag, is saturated with matter from the inoculated pustules of the preceding year, for they never 
inoculate with fresh matter, nor with matter from the disease caught in the natural way, howeverdistinct and mild the species. He then proceeds to give instructions for the treatment of the patient through the course of the process, which are most religiously observed.

The instrument they make use of, is of iron, about four inches and a half long, and of the size of a large crow quill, the middle is twisted, and the one end is steeled and flatted about an inch from the extre mity, and the eighth of an inch broad; this extremity is brought to a very keen edge, and two sharp corners; the other end of the instrument is an earpicker, and the instrument is precisely the same as the Barbers of Indostan use to cut the nails, and depurate the ears of their customers, (for in that country, we are.above performing either of these operations ourselves) The Operator of inoculation holds the instrument as we hold a pen, and with dexterous exepedition gives about fifteen or sixteen minute scarifications (within the compass above men tioned) with one of the sharp cormers of the instru ment, and to these various little wounds, I believe may be ascrbed the discharge which almost constantly flows from the part in the progress of the disease. I cannot help thinking that too much has been said (pro and con) about nothing, respecting the different methods preferred by different practitioners of performing the operation; provided the matter is thrown into the blood, it is certainly, a consideration of most trivial import by what means it is effected; if any claims a preference, I should conclude it should be that method which bids fairest for securing a plentiful discharge from the ulcer."

I am sure that this method of vaccinations has not been bettered even in the Jenner's vaccination technic. It is time that we look into the wisdom in our country rather than look for western thoughts in many things of day to day importance. The Royal Society sent many other scholars to India in the 18 th century to study Indian wisdom and all that is available in the archives of the Royal Scoiety in London. 